\title{
RESILIENSI DIRI DAN STRES KERJA PADA GURU SEKOLAH DASAR
}

\author{
Zarina Akbar* \\ Rizky Pratasiwi** \\ *Fakultas Pendidikan Psikologi, Universitas Negeri Jakarta \\ **Fakultas Pendidikan Psikologi, Universitas Negeri Jakarta
}

DOI: https://doi.org/10.21009/JPPP.062.08

Alamat Korespondensi:

zarina_akbar@unj.ac.id

\begin{abstract}
This Research aims to review the relationship between resiliensi and job stress on primary school teachers.This research using quantitative methods.Samples to this study were $100(n=100)$ using purposive sampling technique.The data using a questionnaire resilience quotient test and teacher stress inventory (TSI). The analysis used using spss 23.0 version. Based on the research, we got the result of notation statistics $r=-0.41 ; p=0.000<0.05$ (significant). The result of this research indicated there are significant negative relationship between resiliensi themselves to stress work in primary school teachers. Much value p produced is -0.41 on significance 0.05 standard.
\end{abstract}

Keywords

resiliens, job stress, primary school, teachers

\section{Pendahuluan}

Peran seorang guru dalam dunia pendidikan merupakan elemen kunci agar sistem pendidikan, khususnya di sekolah bisa berjalan dengan baik (Direktorat Tenaga Kependidikan, 2008). Guru menjadi titik pusat dalam melakukan pembaharuan dan peningkatan mutu pendidikan. Denga Peran seorang guru dalam dunia pendidikan merupakan elemen kunci agar sistem pendidikan, khususnya di sekolah bisa berjalan dengan baik (Direktorat Tenaga Kependidikan, 2008). Guru menjadi titik pusat dalam melakukan pembaharuan dan peningkatan mutu pendidikan. Dengan kata lain salah satu syarat penting untuk mewujudkan pendidikan yang bermutu adalah dengan menempatkan tenaga pendidik yang professional dan memiliki kinerja yang handal. Hasil belajar siswa atau tinggi rendahnya mutu hasil belajar siswa sangat tergantung pada kemampuan guru dalam melakukan pengajaran di kelas. Guru yang memiliki kemampuan mengajar dan kinerja yang baik akan membawa dampak peningkatan pada proses pembelajaran yang baik pula (Riyani, 2012).

Guru sekolah dasar (SD) menduduki posisi yang sangat penting dalam memberikan pendidikan awal. Tanpa guru yang profesional, tidak mungkin mendapatkan pendidikan yang berkualitas. Peningkatan kualitas guru SD sebagai pilar utama pembentukan sumber daya manusia harus menjadi perhatian utama (Faizal \& Yustinus, 2004). Pendidikan SD merupakan pilar utama karena anak berada pada tahap operasional konkret yang mencerminkan pendekatan yang terbatas pada dunia nyata. Pada tahap ini, anak dapat membentuk konsep, melihat hubungan dan memecahkan masalah (Faslah, 2011). Seorang guru yang mengajar di kelas 1 SD dengan hanya ceramah (verbalisme) dalam menerangkan konsep pertambahan pada matematika tidak akan membuat siswa berkembang secara maksimal, 
berbeda jika guru tersebut menggunakan berbagai benda konkret sebagai media untuk menyampaikan materi. Pada anak usia tersebut perkembangan berpikir melalui benda konkret sampai berpikir secara abstrak. Sanaky (dalam Fatimah dan Supriyono, 2013) mengemukakan, dalam belajar melibatkan benda asli merupakan alat yang efektif. Hal ini disebabkan benda asli memiliki sifat keasliaanya, mulai dari ukuran besar dan kecil, berat, warna, dan adakalanya disertai dengan gerak dan bunyi, sehingga memiliki daya tarik sendiri bagi siswa. Benda konkret adalah benda dalam keadaan sebenarnya dan seutuhnya. Benda konkret merupakan salah satu media yang memanfaatkan benda-benda nyata di lingkungan sekitar. Benda konkret digunakan sebagai media dalam rangka memudahkan siswa lebih memahami materi yang disampaikan oleh guru.

Hasil dari studi pendahuluan dapat dikatakan guru SD memiliki tugas mengajar yang monoton dibandingkan guru Sekolah Menegah Pertama (SMP) atau Sekolah Menengah Atas (SMA). Guru sekolah dasar yang mengajar kelas 1 dan 2 pada umumnya menjadi guru kelas yang setiap hari nya bertemu dengan siswa yang sama dan mengajar dari pagi hingga sore semua mata pelajaran yang di jadwalkan (Ayuningtyas, 2013). Selain menjelaskan mata pelajaran dan memberikan tugas kepada siswa, guru juga bertanggung jawab atas perkembangan hasil yang dicapai oleh siswa. Guru SD dapat dikatakan bekerja sehari penuh untuk memberikan pelajaran kepada anak didiknya terlebih ketika menjadi guru kelas, keadaan-keadaan tersebut yang menyebabkan terjadinya kecenderungan mengalami stres kerja. Penelitian yang dilakukan Dewi (2007) yang dilakukan di kecamatan Pakis Magelang, menunjukkan bahwa tingkat stres kerja guru SD lebih tinggi dibandingkan dengan guru SMP.

Menurut Mulyasa (2007) profesionalisme guru di Indonesia masih sangat rendah, hal tersebut disebabkan karena belum adanya perubahan pola mengajar dan sistem konvensional ke sistem kompetensi, beban kerja guru yang tinggi, dan masih banyak guru yang belum melakukan penelitian tindakan kelas.

Berdasarkan studi pendahuluan yang dilakukan oleh peneliti, melalui wawancara guru sekolah dasar di Jakarta Timur diketahui bahwa beban pekerjaan seorang guru saat ini tergolong berat.
Kurikulum yang berubah setiap tahun menuntut guru untuk bekerja cepat menyelesaikan tugas mereka ditambah dengan peraturan UndangUndang Dasar yang mewajibkan seorang guru mengajar tatap muka minimal 24 jam/minggu. Seorang guru tidak hanya bertugas mengajar di depan kelas, memeriksa tugas murid dan membuat rancangan pembelajaran (RPP). Namun, seorang guru juga bertanggung jawab terhadap tingkat prestasi akademik anak didiknya, terlebih ketika seorang guru tersebut ditugaskan untuk menjadi seorang guru kelas. Adanya sistem ERapport menambah beban guru. Guru diwajibkan memasukkan nilai ke dalam server komputer. Tidak sedikit pula guru yang menginap menjelang kenaikan kelas, karena server komputer yang mengalami gangguan. Guru tidak hanya berperan sebagai pengajar, guru juga memiliki peranan lain seperti ibu rumah tangga, tokoh yang berperan aktif dalam masyarakat dan ketika berada di tengah masyarakat guru merupakan figur teladan yang memberikan kontribusi positif dan norma sosial. Sebagian guru juga mengeluhkan gangguan fisik seperti pusing dan sulit tidur. Tuntutan yang ada harus mewajibkan seorang guru harus tetap bersikap profesional.

Menurut Howard dan Jhonson (2002) stres pada seorang guru dapat timbul dari faktor lingkungan kerja yang buruk dan tidak mendukung proses belajar mengajar. Oleh karena itu, seorang guru harus mempunyai kepribadian yang matang, tegar, dan kemampuan untuk menghadapi maslah yang dihadapi. Kemampuan dalam mempertahankan diri dari stres disebut resiliensi (Diah \& Pradna, 2012). Menurut Kuiper (dalam Diah \& Pradna, 2012) menyatakan bahwa resiliensi merupakan bagian dari psikologi positif, resiliensi akan mengarahkan individu untuk memaknai kembali kualitas hidup dan mengarahkannya pada gaya hidup yang positif. Hasil akhir yang diharapkan dari resiliensi adalah untuk membentuk individu untuk memaknai kembali kualitas hidup dan mengarahkannya pada gaya hidup yang positif. Hasil akhir yang diharapkan dari resiliensi adalah untuk membentuk individu yang mampu menghadapi stres dan trauma yang menimpa.

Stres yang dihadapi oleh guru tidak hanya terjadi di sekolah, namun masalah yang memicu terjadi nya stres pada guru adalah lingkungan luar 
sekolah jauh lebih kompleks. Kondisi-kondisi seperti macet, letak geografis yang jauh, hiruk pikuknya perkotaan, tuntutan peraturan yang dibuat oleh $\mathrm{n}$ kata lain salah satu syarat penting untuk mewujudkan pendidikan yang bermutu adalah dengan menempatkan tenaga pendidik yang professional dan memiliki kinerja yang handal. Hasil belajar siswa atau tinggi rendahnya mutu hasil belajar siswa sangat tergantung pada kemampuan guru dalam melakukan pengajaran di kelas. Guru yang memiliki kemampuan mengajar dan kinerja yang baik akan membawa dampak peningkatan pada proses pembelajaran yang baik pula (Riyani, 2012).

\section{Metode Penelitian}

Penelitian untuk mengetahui apakah ada hubungan negatif signifikan antara resiliensi diri dengan stres guru sekolah dasar ini menggunakan metode kuantitatif, yaitu suatu telaah empiris sistematis dimana peneliti tidak dapat mengontrol variabel bebas secara langsung karena sifat variabel tersebut tidak dapat dimanipulasi
(Kerlinger, 2002). Subjek dalam penelitian ini adalah 100 guru sekolah dasar negeri yang berstatus sebagai Pegawai Negeri Sipil dengan minimal pengalaman mengajar selama 1 tahun.

Pengumpulan data bisa dilihat dari segi cara dapat dilakukan dengan meggunakan kuesioner. Alat ukur stres kerja guru menggunakan Teacher Stress Inventory yang dibuat oleh J. Fimian dan Resilience Quotient Test untuk mengukur tingkat resiliensi yang dibuat oleh Reivich \& Shatte. Uji korelasi pada menelitian ini menggunakan product moment. Uji korelasi dilakukan untuk menganalisis hubungan antar variabel serta bagaimana bentuk hubungan yang terjadi antar dua variabel (Rangkuti, 2013).

\section{Hasil Penelitian dan Diskusi}

Hasil analisis data menggunakan product moment menunjukkan notasi statistik $\mathrm{r}=-0.41 ; \mathrm{p}$ $=0.000<0.05$ (Signifikan). Penelitian ini menunjukkan terdapat hubungan negatif signifikan antara resiliensi diri dengan stres kerja pada guru sekolah dasar.

Tabel 1. Tabel Korelasi Product Moment

\begin{tabular}{ccccc}
\hline Variabel & Nilai $\mathbf{r}$ & Nilai $\boldsymbol{p}$ & Sig. & Interpretasi \\
\hline $\begin{array}{c}\text { Resiliensi } \\
\text { dengan stres kerja }\end{array}$ & $-0,41$ & 0.000 & 0.05 & $\begin{array}{c}\text { Terdapat } \\
\text { hubungan negatif yang } \\
\text { signifikan }\end{array}$ \\
\hline
\end{tabular}

Hasil penelitian ini menunjukkan bahwa stres kerja mempunyai hubungan negatif signifikan terhadap resiliensi. Dalam hal ini ketika stres yang tinggi dialami oleh seseorang maka kinerja yang dia hasilkan akan menurun. Stres yang terjadi ditunjukkan dengan merasa gelisah, merasa marah, dan merasa kesulitan dalam melakukan pekerjaannya. Semakin bertambah sulitnya pekerjaan disebabkan oleh beban tugas yang berlebihan, dan keadaan di luar kontrol yang terjadi saat proses belajar mengajar. Dengan semakin sulitnya tugas yang dihadapi hal tersebut akan menyebabkan perasaan stres yang dirasakan oleh guru. Ketika seorang guru memiliki resiliensi diri yang rendah akan mengakibatkan menurunnya kinerja yang dihasilkan.

Penelitian yang dilakukan juga terkait dengan penelitian Puspitasari \& Handayani (2014) yang menunjukkan adanya hubungan yang signifikasi antara efikasi diri dengan tingkat burnout. Efikasi diri merupakan salah satu aspek resiliensi diri yang dapat diartikan keyakinan seseorang dalam mengatur situasi yang akan datang. Efikasi diri membantu seseorang menangani keadaan sulit yang pada umumnya seseorang cenderung menghindari tugas yang dianggap berat. Seseorang yang mencoba menemukan solusi dari permasalahan yang dihadapinya ketika memiliki efikasi diri yang tinggi ia akan mencari tahu upaya apa yang kurang yang telah dilakukannya. Sebaliknya, jika efikasi diri yang dimiliki rendah ia menganggap kegagalan disebebabkan oleh kemampuannya yang kurang. Guru yang memiliki efikasi diri yang rendah mudah bagi dirinya mengalami stres kerja oleh karena nya seorang guru harus memiliki efikasi diri yang tinggi serta kemampuan bertahan dalam menghadapi berbagai kesulitan hidup. 


\section{Kesimpulan}

Berdasarkan hasil penelitian yang telah dilakukan, dapat disimpulkan terdapat hubungan antara resiliensi diri dengan stres kerja pada guru sekolah dasar. Hasil pengujian menunjukkan adanya hubungan negatif signifikan yaitu jika rendah tingkat stres kerja, maka tingkat resiliensi diri tinggi.

\section{Daftar Pustaka}

Anatan, L., \& Ellitan, L. (2007). Manajemen Sumber Daya Manusia dalam Bisnis Modern. Bandung: Penerbit Alfabeta.

Anwar, P. M., Puspitasari, M. (2011). Kecerdasan Emosi, Stress Kerja dan Kinerja Guru SMA. Jurnal Kependidikan, 45(2), 142155.

Ambara, D. (2015). Pengaruh Tingkat Stress Guru terhadap Manajemen Kelas di Sekolah Menengah Atas. Retrieved from download.portalgaruda.org/article.

Arnold, H. J., Feldman, D. C. (1986). Organizational Behavior. McGrawhill Book Company, International Edition.

Avraamidou, L. (2016). Studying Science Teacher Identity: Theoretical, Methodological and Empirical Explorations. Rotterdam: Sense Publishers.

Ayuningtyas, N. K. (2013). Pengaruh antara self efficacy, kepuasan kerja dan stres kerja terhadap guru SD (Tesis). Retrieved from http://www.lib.ui.ac.id/

Azwar, S. (2012). Penyusunan Skala Psikologi. Yogyakarta: Pustaka Pelajar.

Bryan, J. (2005). Fostering Educational Resilience and Achievement in Urban Schools Throught School Family Community Partnerships. ASCA Journal, 3(3).
Coleman, J. C., Carson, R. C., Butcher, J. N. (1984). Abnormal Psychology and modern life ( $7^{\text {th }}$ Edition). Illinois: Scott, Foresman \& Company.

Coleman, J., Hagell, A. (2007). Adolescence, Risk and Resilience. England.

Colvin, H. M., Taylor, R. M. (2012). Building a Resilient Workforce. Washington DC: National Academies Press.

Day, C., Gu, Q. (2014). Resilient Teachers, Resilient Schools. Unites Kingdom: Taylor \& Francis LTD.

Dewi, D. R. (2007). Perbedaan Tingkat Stres Kerja antara Guru SD dan Guru SMP. Skripsi. Universitas Sanata Dharma.

Diah, R., Pradna, P. (2012). Resiliensi Guru di Sekolah Terpencil. Jurnal Psikologi Pendidikan dan Perkembangan, 2(1).

Direktorat Tenaga Kependidikan. (2008). Penilaian Kinerja Guru. Jakarta: Direktorat Tenaga Kependidikan, Dirjen PMPTK, Depdiknas.

Faslah, A. (2011). Pencapaian Program Wajib Belajar 9 Tahun. Retrived from http://www.kompasiana.com

Faizal, M. H., Yustinus, S. (2004). Pengaruh Circulo Message terhadap Penurunan Perasaan Kelelahan Kerja pada Guru Wanita Sekolah Dasar Negeri di Kelurahan Bener, Tegalrejo, Yogyakarta. Jurnal Lembaga Pengandian kepada Masyarakat Universitas Gajah Mada.

Fimian, J., Fastenau, P. (1990). The Validity and Reability of the Teacher Inventory: A ReAnalysis of Aggregate Data. Journal of Organizational Behavior, 11(2), 151-157. 
Frankenberger, T. R., Constas, M. A., Nelson, S., \& Starr, L. (2014). Resilience Programming among Nongovernmental Organizations Lessons for Policymakers. Washington: International Food Policy Research Institute.

Greenberg., Jerrold. (2012). Comprehensive Stress Management, Seventh Edition. New York: McGraw-Hill.

Grotberg, E. H. (1999). Tapping Your Inner Strength. Oakland: New Harbinger Publication, Inc.

Gu, Q., Day, C. (2007). Teachers Resilience: A Necessary Condition for Effectiveness. Journal Teaching and Teacher Education, 1302-1317.

Hawari, D. (2006). Manajemen Stres, Cemas dan Depresi. Jakarta: Balai Penerbit FKUI.

Howard, S., Jhonson, B. (2002). Resilient Teachers: Resisting Stress and Burnout. Journal of Social Psychology of Education, 7, 399-420.

Ivancevich, J. M., Konopaske, R., \& Matteson, M. T. (2007). Perilaku dan Manajemen Organisasi (Edisi 7). Jakarta: Erlangga.

Jones \& Bartlett. (2004). Stress Management. Boston.

Kompetensi.info/kompetensi-guru/definisi-gurumenurut-undangundang.html

Kunandar. (2007). Guru Professional Implementasi Kurikulum Tingkat Satuan Pendidikan (KTSP) dan Sukses dalam Sertifikasi Guru. Jakarta: PT. Raja Grafindo Persada.

Kurnia, I. (1995). Kebutuhan dan Profesionalisasi Guru SD. Paper presented at lib.atmajaya.ac.id. Jakarta, 1-33.
Mahmud, D. M. (1990). Psikologi Pendidikan Suatu Pendekatan Terapan. Yogyakarta: BPFE.

McCubbin, L. (2001). Challenges To The Definition of Resilience. Journal of American Psychological Association. 122.

Monks, F. J. (2004). Psikologi Perkembangan; Pengantar dalam Berbagai Bagiannya. Yogyakarta: Gajah Mada University Press.

Morris, J. (1978). Psychology and Teaching: A Humanistic View. New York: Random House.

Mulyasa, E. (2007). Standar Kompetensi dan Sertifikasi Guru. Bandung: Remaja Rosdakarya.

Nuryanto. (2010). Korelasi Tingkat Stress terhadap Kinerja Guru di MTs Al-.Manar Semarang. Skripsi. Sekolah Tinggi Agama Islam Negeri Salatiga.

Prihastuti. (2011). Profil Resiliensi Pendidik Berdasarkan Resilience Quetient Test. Jurnal Pendidikan dan Evaluasi Pendidikan, 15(2), 199-214.

Puspita. D. A., Handayani. M. (2014). Hubungan Tingkat Self-Efficacy Guru dengan Tingkat Burnout pada Guru Sekolah Inklusif di Surabaya. Jurnal Psikologi Pendidikan dan Perkembangan, 1(3).

Rangkuti, A. A., \& Wahyuni, L. D. (2016). Konsep dan Teknik Analisis Data Penelitian Kuantitatif Berbasis Classical Test Theory dan Item Response Theory (Rasch Model). Jakarta: FIP Press.

Rangkuti, A. A. (2012). Konsep dan Teknik Analisis Data Penelitian Kuantitatif Bidang Psikologi dan Pendidikan. Jakarta: FIP Press. 
Rangkuti, A. A (2013). Statistika Parametrik dan Non-Parametrik dalam Bidang Psikologi dan Pendidikan. Jakarta: FIP Press .

Reivich, K., Shatte., Andrew. (2003). The Resilience Factor: 7 Keys to Finding Your Inner Strength and Overcoming Life's Hurdles. New York: Broadway.

Rice, L. P. (1992). Stress and Health. California: Brooks/Cole Publishing.

Robbins, S. P., Judge, Timothy A. (2008). Perilaku Organisasi (Buku 2, Edisi 12). Jakarta.

Rusman. (2014). Model-Model Pembelajaran. Jakarta: Rajawali press.

Riyani, Y. (2012). Faktor-faktor yang Mempengaruhi Prestasi Belajar Mahasiswa (Studi pada Mahasiswa Jurusan Akutansi Politeknik Negeri Pontianak). Jurnal Eksos, 1(8), 19-25.

Robbins. (2003). Perilaku Organisasi (Tim indeks, Penerjemah). Jakarta: Indeks.

Sarwono, P. (2006). Hubungan Masa Kerja dengan Stres Kerja pada Pustakawan Perpustakaan Universitas Gajah Mada Yogyakarta. Berkala ilmu perpustakaan dan Informasi, 3(1), 44-56.
Sudarnoto, L. F.(1997). Tinjauan pada Perkembangan Kognitif menurut Teori Piaget. Makalah. Fakultas keguruan \& ilmu pendidikan Unika Atmajaya, Jakarta.

Sumintono, B. (2014). Aplikasi Model Rasch: Untuk Penelitian Ilmu-Ilmu Sosial. Bandung: Trim Komunikata Publising House.

Sukadiyanto. (2010). Stress dan Cara Menguranginya. Cakrawala pendidikan, 1.

Sutarmanto. (2013). Kompetensi dan Profesionalisme Guru Pendidikan Anak Usia Dini. Jurnal Visi Ilmu Pendidikan, 16.

Uno, H. B. (2010). Perencanaan Pembelajaran. Bandung: Bumi Aksara.

Walker., Holling., Carpener., \& Kinzig. (2004). Resilience, Adaptability and Transformability in Social-Ecological System. Ecology and Society, 9(2).

Walsh., Froma. (2011). Strengthening Family Resilience (2 ${ }^{\text {nd }}$ Edition), New York.

Woolfolk., Anita. (1987). Educational Psychology (3 th edition), New Jersey: Prentice-Hall, Inc. 